\title{
Increasing Competency In Health Science Education: Introspection
}

Sushmita Ghosh Ph.D., Tiffin University, USA

\begin{abstract}
Before health science can play its expected role, health science education needs to be looked at critically and revamped. This area of education needs immediate attention for positive and effective change. This paper is based on observations, deliberations, and supportive findings across the US system of science education. However, with globalization, a lot of it is applicable to other countries. Health science education has been categorized into three categories: Health Science Education in School; in College; And, Beyond College. The paper raises more questions that we need to find workable answers to. It does not, in anyway, claim to provide the best solution, the only answer, or the end to all discussion and development for improvement.
\end{abstract}

Keywords: Health, Science; Education; Fundamentals; School; College; Foundation; Teaching; Oversight; Communications; Competition; Collaboration; Focus; Career; Oversight; Institutional; Resources; Competencies

\section{INTRODUCTION}

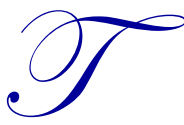

hroughout this paper the term "science" includes Health Science. With an increasing population, economic downturns, rise in the number of elderly people worldwide, and public concerns about health issues, health science has a bigger role to play than ever before. However, before health science can play its expected role, health science education needs to be looked at critically and revamped. Science, as we very well know, is essential for social development and the maintenance and wellbeing of society (Bower 2005). However, like all essentials, science too has numerous challenges. For example, Stinner (1995) had raised and tried to address the question of motivating students in science. Most importantly, how do we ensure that we have a well trained younger generation, who will be able to shoulder the needs of science for society? In 2006 the National Science Foundation reminded us that science education needed to be overhauled. In 2007, NSF reiterated the need to look into specific action items to improve science education (Bryn, 2011). Even though time has passed, Sharp in 2009 aptly pointed out again that changes in science education will be critical in meeting societal challenges (AAAS, 2009). Therefore, this area of education needs immediate attention for positive and effective change.

That raises more questions that we need to find workable answers to. Much of this paper is based on observations, deliberations, and supportive findings across the US system of science education. However, with globalization, a lot of it is applicable to other countries. The paper does not, in anyway, claim to provide the best solution, the only answer, or the end to all discussion and development for improvement.

\section{CATEGORIES}

For the sake of convenience, health science education has been categorized into three categories:

1. Health Science Education in School - From Grade 1 or first standard to Grade 12 or twelfth standard.

2. Health Science Education in College - Bachelors, Masters, Doctoral Studies, and Professional Degrees

3. And, Beyond College - After graduation from College and University and joining the workforce 


\section{SCHOOL (K-12)}

\section{Foundation}

In a way, there is a lot of education in the area of health sciences in K-12. At the same time, there are not enough students who graduate with sufficient understanding or appreciation for the health sciences. There is also vast inconsistency in the quality of education in health sciences that students receive from different schools in different geographical areas.

There is concern whether students are receiving a strong foundation in science. With the constant pressure to know all about everything and to be at the cutting edge often results in superficial awareness and no understanding. When the foundation is weak, everything else built upon it is questionable. Scientists have expressed concern that students receive "a mile wide of information and an inch deep of knowledge." Just take a look at the library that students carry to school for their daily classes. Often the textbooks have colorful photos that may not even have any relevance to the subject matter. Students today do not get sufficient time to absorb the material into long term memory. You rush through chapters, take an exam, and forget for good. What a miserable waste of time and effort!

Additionally, students are driven to applications before they have assimilated the concepts. Conflicting misconceptions complicate matters further. Experts in various fields underscore the fact that memorization should be eradicated. However, in the case of health sciences, there is a huge bag of terminology that needs to be remembered. From a practical standpoint, an efficient and effective replacement for memorization of health science terms, a lot of which is in Latin, has not yet been successfully developed.

\section{Teaching}

Teachers are often pressured to teach toward successful scores on tests rather than teaching the subject for understanding and implementation. There are guides, tutoring etc. to achieve higher scores on a test and little certainty that there is an accompanying increase in understanding of subject matter. Grades and scores become the be all and end all of science education. If somebody does poorly on a test, they are discouraged from pursuing the subject (Barnes, Slate, and Rojas-LeBouef 2010). There is also the challenge of completing too much in too little time. There is little or no time provided to the student to absorb the material well before proceeding to the next challenging level of study. There is also the question of individual competency - does everybody need to know health science in depth at the K-12 level?

\section{Qualified Teachers}

With the shortage of teachers and financial resources, several schools are tempted into getting by with any warm body available at a cheap price. The lack of effective teaching skills adds to the problem (Mooney 2009). Together they raise the question of "focus" - Should schools focus on expertise on subject matter or is it just sufficient if students attended a certain number of classes labeled under the "science" category? Often governments practice budgetary discipline at the expense of funds for education. Teachers are more often than not in the first short list for pay cuts and retrenchment. It is challenging for several individuals to plan a career and invest all their resources on an uncertain and often financially risky career. No wonder we routinely face a shortage in the number of qualified teachers for health sciences. With a little bit of enterprise, the would be teachers could move away to higher paying and more stable employment in applied fields.

\section{COLLEGE}

\section{General Education}

In the US education system, all students pursuing a degree in any field are required to take what are called general education courses. The purpose is to provide students a holistic educational foundation, which will enable them to appreciate the place and role of their field of study in society. The question is what courses should be 
included in this list to make meaningful progress towards achieving this purpose of holistic education? How does their focus and mastery of their major field of study allow them to contribute to society and the general public? General education courses are an area that is very difficult to change. Individuals look at the same things differently. In a democratic society, it takes longer to bring change, especially when a certain list of courses has been in place for years, if not decades. Also, there is a standard four years allocated to completing college. Although many students stay in college longer even if they have successfully completed all courses taken, this psychological fouryear time limit often hinders adding additional courses to a student's curriculum plan. Also the financial expenses of staying in college longer than four years in a society where the student is personally responsible for paying the same, the opportunity cost of staying longer is a concern. Should some of the general education courses give way to more courses in health sciences for those in the field?

\section{Oversight of Institutional Resources}

When looking into funding for programs, one would question who should be making the decisions on allocation of financial resources -- should it be the academic experts in the field, or should it be professional administrators who may not have an in-depth knowledge of the field and its requirements? Also, the limited resources have to be divided between priorities. These priorities are funds for research so the teacher can be abreast of cutting-edge developments in the field of study and funds for basic fundamental teaching with no distractions. Teaching health science without substantial investment in laboratories is near impossible.

\section{Communications Competencies of Health Science Students}

Several health science students are highly competent in their fields but are handicapped by their inability to communicate effectively with people with backgrounds other than health science. One may be a genius but may not be understood by the vast majority that is not. Scientists will have to develop the strong ability to communicate with others for funding decisions or the decisions to move a project forward. Often such decisions are made by lay people. Such communications abilities will have to be taught. Here comes the questions of responsibility - Who is responsible for teaching communications competencies? Science faculty or communications faculty? How do we identify teachers who are competent in both science and communications? Are there individuals who are both competent in their field and also capable of teaching across disciplines? Can a communications expert teach in the science context? What are other comparable alternatives to teaching health science students strong communications skills?

\section{BEYOND COLLEGE}

Health science education does not end when you get a degree. So, let us take a look at improving science education after formal education.

\section{Competition Through Collaboration}

Scientists and scientific organizations should realize that competition is good for advancement and competition through collaboration is a win-win proposition. In an era of limited resources, it is sensible to ensure that expensive replication of efforts consuming precious resources may result in many critical projects being shelved or eliminated. With collaboration, critical resources including finances can be shared and more can be achieved with less.

One potential step would be to develop a central knowledge database online with open access to the community of scientists worldwide. Yes, people may raise the question of security and potential abuse of knowledge from the database. Ways and means will have to be developed for screening safe scientists. These safe scientists worldwide should also be provided access to firsthand observation of scientific facilities worldwide. 


\section{Focus}

A scientist is first and foremost an observer, experimenter, and developer for furthering human understanding of the laws of nature in order to apply those findings and results to the development of usable applications for society's progress. We have to focus on maximizing the scientist's use of time productively for maximizing benefits to society. We often, probably unintentionally, form clubs to censor much of scientific knowledge that does not conform to favorite theories and formats of presentation.

Being politically correct is an important challenge for health scientists. Should health scientists be protected from the demands of shifting political requirements? Is there a strong mechanism for that or should there be some kind of unquestionable right to pursue the advance of health sciences for the common good? One question leads to another, but in the interim till the perfect solution is found, health scientists need the protection of law.

\section{Professional Career Support}

Health science research is normally expensive and results can take decades to materialize. We need a commitment to scientists and ensure support for their careers. Most truly new developments in health science cannot be measured in business quarters -- every 3 months. Most health science research takes years to conduct and certainly longer for breakthroughs. Even after the breakthrough, it takes years to be accepted by peers - the scientific community. Such acceptance comes from presentation in conferences, publication in scientific journals, and then acceptance and adoption by education. There is a big need for major funds to be committed to this area and patience in the waiting game. Major infusion and locking up of funds still do not guarantee success in a fixed timetable.

\section{CONCLUSION}

Improving health science education is and will be an ongoing process of introspection, improvisation, and finding solutions. It is not and will not be a one-time fix. Around the year 1900, there was a very strong movement to close down the US Office of Patents. Politicians and the unknowing public of that time period believed that everything that had to be discovered and invented had already been achieved. We know how wrong they were!

\section{AUTHOR INFORMATION}

Dr. Sushmita Ghosh Ph.D., is Associate Professor of Science at Tiffin University, Tiffin, Ohio. She has published in major scientific journals and worked at The University of Illinois at Urbana-Champaign, and Tulane University, New Orleans, Louisiana. Dr. Ghosh has presented at national and global conferences in USA and abroad. E-mail: ghoshs@tiffin.edu

\section{REFERENCES}

1. AAAS (2009), Vision and Change in Undergraduate Biology Education: A Call to Action. American Association for the Advancement of Science.

2. Barnes, Wally, Slate, John R., Rojas-LeBouef, Ana (2010). College-Readiness and Academic Preparedness: The Same Concepts? Current Issues in Education, Vol. 13, No 4.

3. Bower, James M. (2005). Scientists and Science Education Reform: Myths, Methods, and Madness. National Academy of Sciences.

4. Bryn, Brandon (February $23^{\text {rd }}, 2011$ ) New Report Proposes Historic Renovation of Undergraduate Biology Education in the United States. http://www.aaas.org/news/releases/2011/0223vision_change.shtml Retrieved on February 27, 2011.

5. Mooney, Chris (August $5^{\text {th }}, 2009$ ) What's Wrong with U.S. Science Education? Science Progress. http://www.scienceprogress.org/2009/08/what\%E2\%80\%99s-wrong-with-us-science-education/ Retrieved on May 27, 2010.

6. Stinner, Arthur (1995). Contextual Settings, Science Stories, and Large Context Problems: Toward a More Humanistic Science Education. Science Education, Vol. 79, No. 5, pp. 555-81. Sep. 